\title{
EL ADENOMA HIPOFISARIO DE PERCY WYNDHAM LEWIS (1882-1957)
}

\author{
MIR FULLANA $F^{1}$
}

Este pintor y escritor canadiense nació el día once de noviembre de 1882 a bordo del yate Wanda cerca de la costa americana de Amherst en Nueva Escocia. Tras la separación matrimonial en 1888, Percy y su madre fijaron su residencia en Londres donde estudió en la Rugby School y en la Slade School of Art. Entre los años 1903 y 1908 abandonó la rígida Inglaterra por la vida bohemia de París (1) relacionándose con los movimientos de vanguardia en los que llegó a gozar de buena reputación.

Retornó a Inglaterra con el deseo de renovar el arte inglés y en 1913 fundó, junto con el poeta Ezra Pound, el Rebel Art Center y al año siguiente la revista BLAST cuna del movimiento literario y artístico denominado Vorticismo. El Vórtex era un signo místico bien conocido en los círculos ocultistas y Pound lo definía (2) como el punto de máxima energía. El Vorticismo era un movimiento artístico mezcla de Futurismo y Cubismo con un cierto punto de arrogancia e incluso de fascismo de sus pocos miembros que eran considerados por Lewis como los genios anglosajones.

Durante la I Guerra Mundial Lewis sirvió como oficial artillero. En 1918 se aseguró un puesto como artista oficial de guerra y a pesar que en su primer encargo, la obra Canadian Gun Pit, se vio obligado a comprometer su estilo vorticista, no lo hizo en su famoso cuadro de 1919 A Battery Shelled (3). Tras la guerra pasó unos años estudiando y podría haber sido recordado como un notable escritor de ficción,

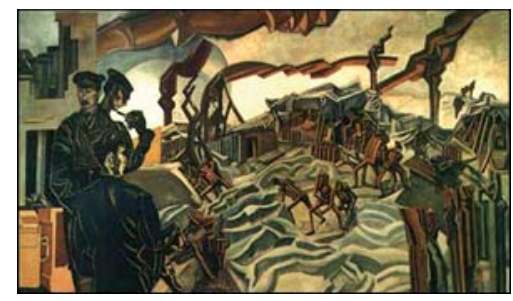

A battery Shelled (1919). como crítico o como periodista polémico más que como artista pintor. Pero en 1931 cometió la mayor equivocación de su vida al escribir la obra Hitler donde loaba el Nacional Socialismo considerando al dictador como un enviado para traer la paz a Europa. A pesar que pronto cambió de idea y escribir en 1939 dos obras satíricas, The Jews, Are they human? y The Hitler Cult, el daño ya estaba hecho y tuvo que emigrar a los Estados Unidos para huir de la impopularidad. Una vez allí, Lewis se vio envuelto en una nueva controversia al iniciar una campaña contra el arte abstracto ya que el estilo de Lewis había cambiado, era más figurativo y se oponía a la extrema abstracción de los expresionistas abstractos como Jackson Pollok.

En la década de 1940 Lewis fue perdiendo la vista de forma gradual debido a un adenoma hipofisa-

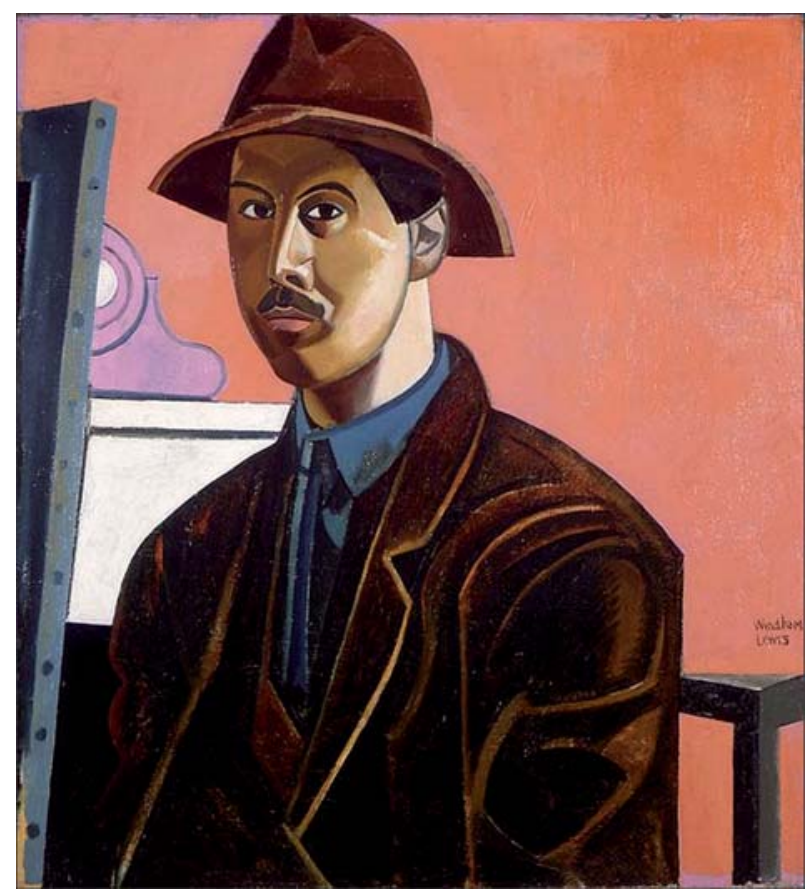

Autorretrato (1921).

\footnotetext{
1 Oftalmólogo.

E-mail: Fmir@mutuabalear.es
} 


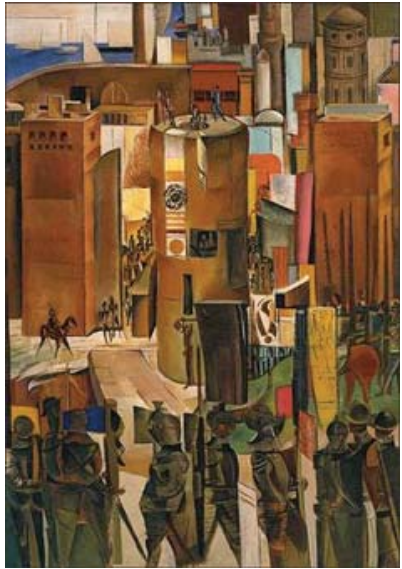

El sueño de Barcelona (1937).

rio que comprimía el quiasma óptico, retornando a Inglaterra en 1945.

La unidad neuroendocrina formada por la hipófisis y el hipotálamo constituye el director de orquesta del sistema endocrino. Los adenomas hipofisarios son tumoraciones que casi siempre presionan al quiasma óptico, lugar de entrecruzamiento de los nervios ópticos. Las fibras ventrales, procedentes de las retinas nasales inferiores, son las que muestran los primeros signos de compresión que se traducen por defectos campimétricos temporales bilaterales superiores constituyendo una cuadrantanopsia bilateral superior. Si la tumoración crece, las fibras superiores de los nervios ópticos que se entrecruzan también son comprimidas traduciéndose en defectos bilaterales de los campos visuales temporales inferiores constituyendo la clásica imagen campimétrica de la compresión infraquiasmática típica de las tumoraciones hipofisarias: la hemianopsia bitemporal.

Los adenomas hipofisarios se originan en las células de tan importante glándula y son tumoraciones benignas, pero si crecen y no se operan, las consecuencias pueden ser terribles: cefaleas por distensión de la duramadre que envuelve la glándula, ceguera por compresión del quiasma óptico, alteración de la motilidad ocular por afectación de los pares III y IV, secreción anómala de hormonas con numerosas alteraciones endocrinas, etc. Si superan los $10 \mathrm{~mm}$ se denominan macroadenomas y sobrepasan la silla turca pudiendo extenderse hacia el quiasma, el hipotálamo, el seno esfenoidal o lateralmente hacia los senos cavernosos cerebrales. Actualmente, los adenomas hipofisarios se diagnostican con precisión gracias a la campimetría computarizada y a la resonancia magnética siendo interve-

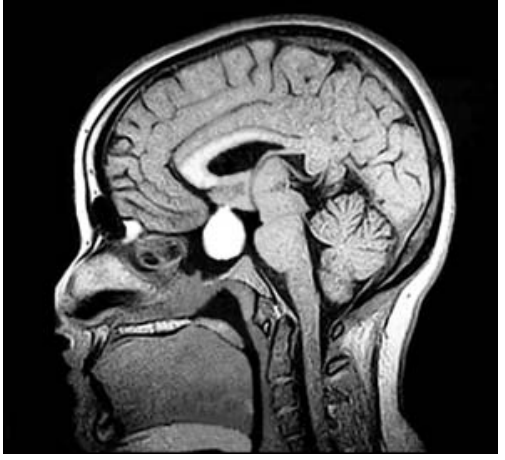

Adenoma hipofisario RMN.

nidos la gran mayoría por vía nasal transesfenoidal con buenos resultados (4).

Pero Lewis padeció el tumor en una época en la que tanto las técnicas de diagnóstico como las neuroquirúrgicas no eran las actuales... y no fue intervenido. Por ello, la tumoración fue creciendo hasta provocarle la ceguera total en 1951 (5). Sin lugar a dudas, la tumoración de Lewis era un macroadenoma hipofisario gigante.

Hay autores que consideran que la cromaticidad de los retratos de Lewis a partir de 1937 podría constituir un signo inicial de su tumoración intracraneal (6). Durante sus últimos años y a medida que disminuía su visión, Lewis se dedicó a redactar libros entre los que destacan su autobiografía SelfCondemned de 1954 y The Human Age de 1955. Finalmente falleció en 1957 por fracaso renal.

Actualmente es considerado el artista inglés más original de la primera parte del siglo XX, pero su obra escrita es muy difícil de evaluar por su contenido utópico y sus continuas contradicciones.

Un excelente retrato de Lewis realizado por Michael Arton en 1955, actualmente en la Tate Gallery de Londres, lo representa con un estado general muy deteriorado y ciego debido a la tumoración.

\section{BIBLIOGRAFÍA}

1. Myers J. The Enemy. A biography of Wyndham Lewis. Londres: Routhledge\&Kegan Paul, 1980.

2. Wees WC. Vorticism and the English Avant-Garde. Manchester: Manchester University Press, 1972.

3. Michel W. Wyndham Lewis. Paintings and Drawings. Londres: Thames\&Hudson, 1971.

4. Wormington CM. Pituitary adenoma: diagnosis and management. J Am Optom Assoc 1989; 60: 929-935.

5. Lanthony P. La vision des peintres. Lausanne: L'Âge de l'homme, 1999.

6. Conway JF. An early effect of Wyndham Lewis' pituitary tumour on his art. Eye 1988; 2: 677-681. 